\title{
Temporal and spatial variation characteris- tics of present stress field in the northern area of North China"
}

\author{
LI Rui-sha ${ }^{1,3}$ (李瑞莎) CUI Xiao-feng ${ }^{1), 4}$ (崔效锋) DIAO Gui-ling ${ }^{2)}$ (习桂苓) \\ ZHANG Hong-yan ${ }^{1)}$ (张红艳) \\ 1) Institute of Crustal Dynamics, China Earthquake Administration, Beijing 100085, China \\ 2) Earthquake Administration of Hebei Province, Shijiazhuang 050021, China \\ 3) Second Crust Monitoring and Application Center, China Earthquake Administration, Xi'an 710054, China
}

\begin{abstract}
From focal mechanism solutions of the earthquakes in the northern part of North China during the period of 2002 2006, the directions of principal stress axes in 4 stress sub-districts are analyzed using a grid test method. The characteristic of present crustal stress directions is discussed. Based on this result and on the focal mechanism solutions calculated for some events in the period of 1977 1998, in combination with some other study results, the temporal variation of present crustal stress directions in the northern part of North China is investigated. The results confirm that the direction of crustal principal stress in some regions had somewhat rotated after the 1976 Tangshan $M 7.8$ earthquake. The mean $P$ axes of the focal mechanism solutions rotated clockwise not only in Tangshan sub-district, but also in Beijing and Xingtai sub-districts after the Tangshan earthquake. In Beijing and Xingtai sub-districts the orientations of principal stress axes in the period of 2002 2006 are consistent with that before the Tangshan earthquake, implying that the stress orientations has rotated back to the state before the Tangshan earthquake in these two sub-districts. The directions of the mean $P$ axes are nearly E-W in Tangshan sub-district since the M7.8 earthquake. The present stress field in the sub-district northwest to Beijing, or in the western part of the Zhangjiakou-Bohai fault zone, is relatively stable during the time period concerned in this study. Because of the limitation of data, this paper only states a possible variation of stress field in the northern part of North China in the recent decades.
\end{abstract}

Key words: focal mechanism, North China, stress field

CLC number: $\mathrm{P} 315.72^{+} 7 \quad$ Document code: A

\section{Introduction}

Over years, Chinese scholars have carried out studies on the tectonic stress field in North China by making use of ample focal mechanism data in this area and delineated the overall pattern of present tectonic stress field in North China. It is believed that the medium principal stress axis in North China is basically vertical; the maximum and minimum principal axes are nearly in horizontal direction. The direction of the maximum principal stress axis is from ENE to NE. The direction of maximum principal stress axis in the west part of North China is NE, then turns to E-W

\footnotetext{
* Received 2008-04-28; accepted in revised form 2008-07-22.

* Author for correspondence: cuixfeng@sina.com
} 
gradually in the southeastern part of North China and neighboring sea area; the stress trajectories appear as a radial distribution from western land toward coast. (XU et al, 1983; WANG and XU, 1985; WANG and ZHANG, 2002; CHEN et al, 2003).

Besides the spatial inhomogeneity of present tectonic stress field in North China, Chinese scholars also found some temporal variations of present stress field in North China (especially before and after some moderate and strong earthquakes) (ZHAO et al, 1984; ZHOU et al, 2000; FAN et al, 2003). For example, ZHOU et al (2001) analyzed the temporal and spatial variation of stress field in the source area and different tectonic positions around four moderate and strong earthquakes (the 1975 Haicheng earthquake, 1976 Tangshan earthquake, 1983 Heze earthquake and 1995 Cangshan earthquake) by making use of focal mechanism solutions of small earthquakes; some abnormal changes were found in the stress field neighboring to the seismic source area before the earthquake. XU (1985) determined the mean stress field in Tangshan aftershock area by fitting slip directions, found that the maximum principal stress axis in the aftershock area was in near-E-W direction, and the axis rotated about $30^{\circ}$ clockwise compared to the value before the quake. Cui and XIE (2002) made further research by making use of focal mechanism solutions of 126 moderate and strong earthquakes in North China and found that variation region of stress field before and after the Tangshan earthquake is larger; the direction of the maximum principal stress in south-central North China including the Tangshan aftershock area may have rotated clockwise. With improvement of observation technique and development of analytical method, the temporal and spatial heterogeneity of stress field in North China area had been revealed gradually.

However, the studies concerning the rotation and variation of principal stress direction in the past were mainly focused on small area (seismic source area of strong earthquakes) and short time (before and after strong earthquakes), whereas studies on continuous variation of stress field is relatively rare. Since the 1980s, fewer strong earthquakes happened in North China area, while a large number of small quakes were recorded by the seismic network. In view of this situation, we made an analysis of focal mechanism solutions of recent small quakes happened in northern area of North China by the grid test method; a preliminary study on the temporal variation characteristic of stress field in the northern area of North China was carried out based on studies of spatial distribution characteristic of present stress field in northern area of North China.

\section{Focal mechanism solution and division of stress zone}

The method of using $P, B$ and $T$ axes from focal mechanism solutions to infer the direction of stress field is applied extensively. $P$ axis and $T$ axis reflect the change of stress state in seismic source area before and after an earthquake, rather than the tectonic stress of the seismic source area (Yamakawa, 1971). However from the analysis of first motion polarity of a large number of widely distributed moderate and small earthquakes in an area or the $P, B$ and $T$ axes of focal mechanism solutions, the stress directions in this area can be obtained possibly (XU et al, 1983; ZHONG and CHENG, 2006). In the year of 2002, a digital seismic network in Capital Circle was built and put into official operation, since then, moderate and small earthquakes in large quantity in northern area of North China have been recorded. LIANG et al (1984) proposed a focal mechanism inversion method by adopting a point dislocation source model in layered media and fitting the synthetic seismograms to the observed maximum amplitudes of $\bar{P}$ and $\bar{S}$ waves in vertical components. The method is applicable for regional seismic networks. Therefore, we used this method to determine the focal mechanisms of recent moderate and small earthquakes in the north- 
ern area of North China. During the solving process, we looked up numerous earthquake waveform records from the digital seismic network, chose the events with epicentral distance less than $200 \mathrm{~km}$; for each event, at least four stations had readings of maximum $\bar{P}$ and $\bar{S}$ amplitude from vertical components and at least one station recorded clear first motion polarity of $\bar{P}$ wave to ensure the stability and reliability of focal mechanism solution (HU et al, 2004; DIAO et al, 2007). We have obtained altogether 431 reliable focal mechanism solutions from January 2002 to July 2006 in the northern area of North China. The earthquake epicenter distribution is shown in Figure 1; for time and magnitude distribution, see Table 1.

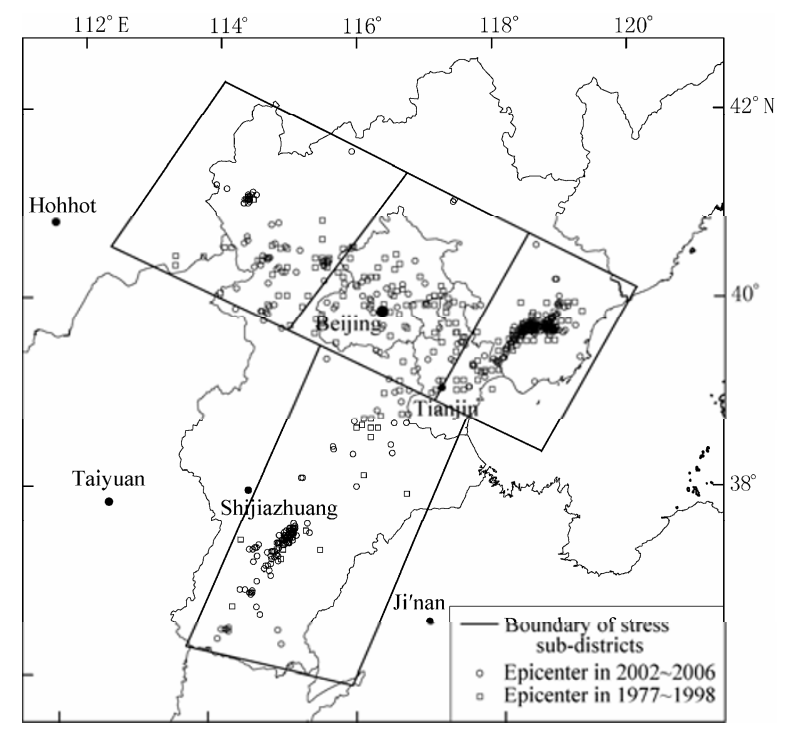

Figure 1 Spatial distribution of earthquakes and the stress sub-districts.

Table 1 The temporal and magnitude distribution of earthquakes in the northern area of North China during 2002 2006

\begin{tabular}{ccc}
\hline Date & Range of magnitude & Number of focal mechanism solution \\
\hline $2002-01 \sim 2002-12$ & $1.6 \sim 4.7$ & 170 \\
$2003-01 \sim 2003-12$ & $2.0 \sim 4.3$ & 84 \\
$2004-01 \sim 2004-12$ & $2.0 \sim 5.0$ & 56 \\
$2005-01 \sim 2005-12$ & $2.0 \sim 3.9$ & 92 \\
$2006-01 \sim 2006-07$ & $2.0 \sim 5.1$ & 29 \\
\hline
\end{tabular}

In order to make better analysis on the temporal variation of the present stress field in northern part of North China, we used the "Crustal Stress Database in China and Adjacent Area" system (XIE et al, 2004) to search and sort focal mechanism solutions in the period from 1977 to 2001, and selected 236 focal mechanism solutions in the period from 1977 to 1998 . Owing to too many data, the parameter and author of every focal mechanism solution in details will not be listed in the thesis. For the distribution of seismic data, see Table 1.

The Zhangjiakou-Bohai fault zone in northern area of North China is the boundary between two active crustal blocks of North China Plain and Yanshan; the fault zone is composed of more than 20 discontinuous faults generally trending NW. This fault zone is one of the seismic structural belts that control recent strong earthquakes. The Bohai M7.4 earthquake in 1969, the Tangshan M7.8 earthquake in 1976, and the Zhangbei M6.2 earthquake in 1998 are all situated at this structural belt (WANG et al, 2004; GUO et al, 2007; FANG et al, 2008). In this paper, based on the 
structural features of this fault belt and the distribution of focal mechanism solutions we divide the research district into four stress sub-districts; the Zhangjiakou-Bohai fault belt and adjacent area is divided into three sub-districts, namely, sub-district northwest to Beijing, Beijing sub-district, and Tangshan sub-district; the plain to the south of Zhangjiakou-Bohai fault belt is taken as a sub-district, namely Xingtai sub-district.

The four stress sub-districts are shown in Figure 1. The yearly distribution of focal mechanism solutions in each sub-district are shown in Figure 2.
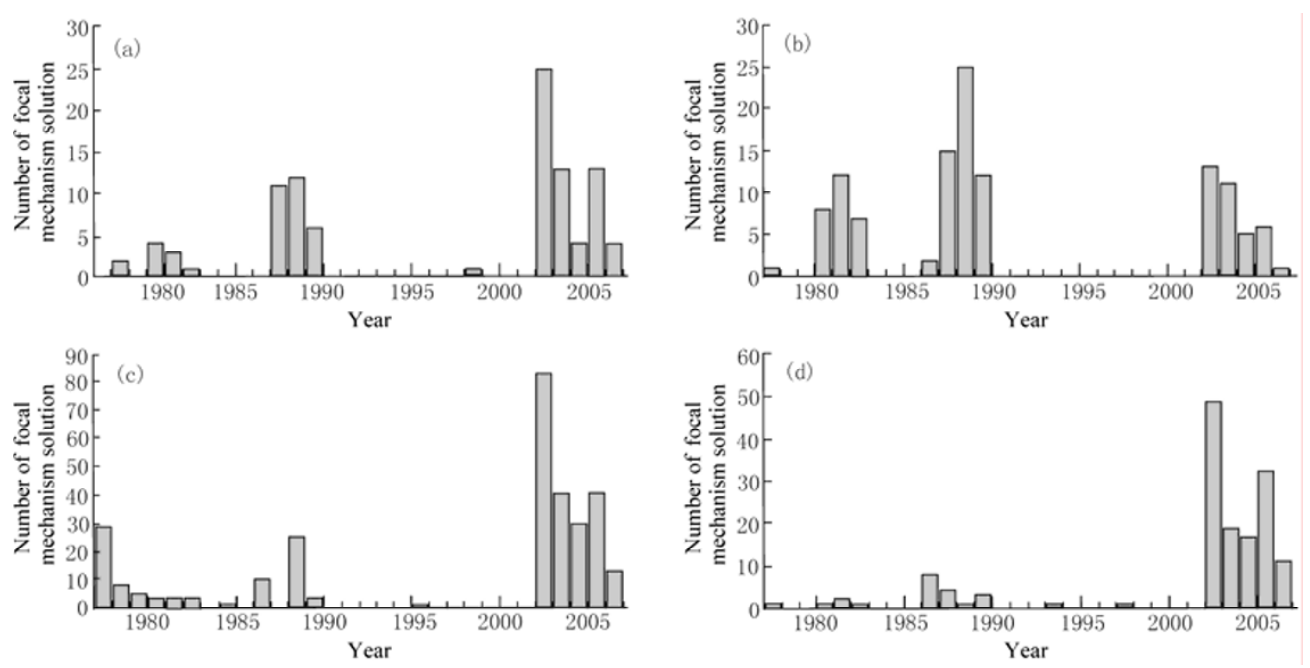

Figure 2 The yearly distribution of the focal mechanism solution date in four stress sub-districts (a) Sub-district northwest to Beijing; (b) Beijing sub-district; (c) Tangshan sub-district; (d) Xingtai sub-district

\section{Analysis of present stress field in northern area of North China based on focal mechanism solutions of moderate and small earth- quakes}

The grid test method for determining the average nodal plane solution of earthquakes using $\mathrm{P}$ wave first motion polarity data of distributed earthquakes in large numbers was put forth by XU et al (1983), it is illustrated through experiments and computation that if earthquakes occur on general pre-existed plane of weakness, the mean $P, B$ and $T$ axes from a number of earthquakes can represent the principal stress axes as long as the number of earthquakes is large enough, and the orientations of fault planes for these earthquakes are comparatively random. After then, some scholars (FAN et al, 2003; WANG et al, 2003) inferred the orientation of mean principal stress axis in the researched area by solving mean $P, B$ and $T$ axes from the $P, B$ and $T$ axes of several focal mechanism solutions with the grid test method.

HU et al (2004) carried out an analysis on the reliability of focal mechanism solutions of moderate and small earthquakes that were determined from the amplitude ratio of $\bar{P}$ and $\bar{S}$ waves; it shows that there are several factors which have influence on the uncertainty of focal mechanism solution; furthermore, moderate and small earthquakes happen randomly, therefore the focal mechanism solutions of moderate and small earthquakes obtained by inversion of amplitude ration could not be taken individually in detailed analysis. The analysis shall take a statistic method on the basis of a large quantity of focal mechanism solutions of moderate and small earth- 
quakes so as to extract the average information and statistic features. It can be observed from Figures 1 and 2 that the 431 focal mechanism solutions of moderate and small earthquakes used in the paper are distributed in space and time. For this reason, we first calculate these focal mechanisms of moderate and small earthquakes by the grid test method; the orientation feature of stress in the four stress sub-districts in the northern area of North China from 2002 to 2006 is analyzed. The detailed steps of analysis and computation are as follows. Take stress sub-district respectively as unit of analysis, and the $P$ and $T$ axes of every focal mechanism solution in the sub-district as upward and downward "first motion polarity" (FAN et al, 2003), and scan all the possible 3-D parameter space with a step length of $5^{\circ} \times 5^{\circ} \times 5^{\circ}$ in order to get the optimum solution for the ratio of contradiction $(\psi)$ to reach the minimum value $\left(\psi_{\mathrm{min}}\right)$. For expressing the possible features of each sub-district clearly, all the possible $P, B$ and $T$ axes between $\psi_{\min }$ and $\psi_{\min }+5 \%$ are given; the distribution range of these axes is titled as the scatter zone. Determine the average orientation of all the possible axes in the end and take it as the orientation of principal axis for stress field in each sub-district.

Table 2 The directions of mean principal stress axes in the northern area of North China during 2002 2006 by the grid test method

\begin{tabular}{|c|c|c|c|c|c|c|c|c|c|}
\hline \multirow{2}{*}{ Sub-district } & \multirow{2}{*}{ Date } & \multirow{2}{*}{$\begin{array}{l}\text { Total num- } \\
\text { ber of earth- } \\
\text { quake }\end{array}$} & \multicolumn{2}{|c|}{ Mean $P$ axis $/^{\circ}$} & \multicolumn{2}{|c|}{ Mean $B$ axis $/{ }^{\circ}$} & \multicolumn{2}{|c|}{ Mean $T$ axis ${ }^{\circ}$} & \multirow{2}{*}{$\begin{array}{l}\text { The lowest } \\
\text {-contradiction } \\
\text { ratio }\end{array}$} \\
\hline & & & Azimuth & inclination & Azimuth & Inclination & Azimuth & inclination & \\
\hline $\begin{array}{l}\text { Sub-district Northwest } \\
\text { to Beijing }\end{array}$ & $2002-03 \sim 2006-07$ & 59 & 75 & 16 & 219 & 70 & 341 & 11 & $12 \%$ \\
\hline Beijing Sub-district & 2002-01 2006-02 & 36 & 65 & 1 & 179 & 87 & 335 & 3 & $17 \%$ \\
\hline Tangshan Sub-district & 2002-01 2006-06 & 208 & 267 & 5 & 52 & 84 & 176 & 3 & $23 \%$ \\
\hline Xingtai Sub-district & 2002-01 2006-07 & 128 & 66 & 5 & 241 & 85 & 336 & 0 & $27 \%$ \\
\hline
\end{tabular}

Table 2 and Figure 3 show the average orientation of principal stress axis from 2002 to 2006 in every stress sub-district in the northern area of North China that were gained by the grid test method. It can be observed that the stress field in northern area of North China has the following features: The mean $B$ axis in the four stress sub-districts is close to vertical with $87^{\circ}$ as the maximum inclination and $70^{\circ}$ as the minimum; the mean $P$ axis and $T$ axis are close to horizontal; all the above indicate that horizontal movement dominates in the present stress field in northern area of North China, the result agrees with that obtained in the past (LI, 1980; WANG and XU, 1985). The orientations of mean $P$ axis and mean $T$ axis in the four stress sub-districts are different obviously. The orientation of mean $P$ axis is ENE in sub-district northwest to Beijing, Beijing sub-district and Xingtai sub-district and the orientation of mean $T$ axis is NWN; whereas the mean $P$ axis in Tangshan sub-district is close to E-W and mean $T$ axis is close to S-N.

From Table 2 and Figure 3 it can be seen that the lowest contradiction ratio in sub-district northwest to Beijing and Beijing sub-district is lower, the scatter zone of possible $P, B$ and $T$ axes is comparatively concentrated with circular or symmetric distribution pattern. The lowest contradiction ratio in Tangshan sub-district and Xingtai sub-district is comparatively higher with relatively wide scatter zone of possible $P, B$ and $T$ axes; while the scatter zone is symmetrical basically. Generally speaking, the data of focal mechanisms of small earthquakes has a good constraining effect on the mean principal stress axis in the four stress sub-districts, and the obtained mean principal stress axes reflect the orientation feature of stress in the four stress sub-districts in northern area of North China from 2002 to 2006. 

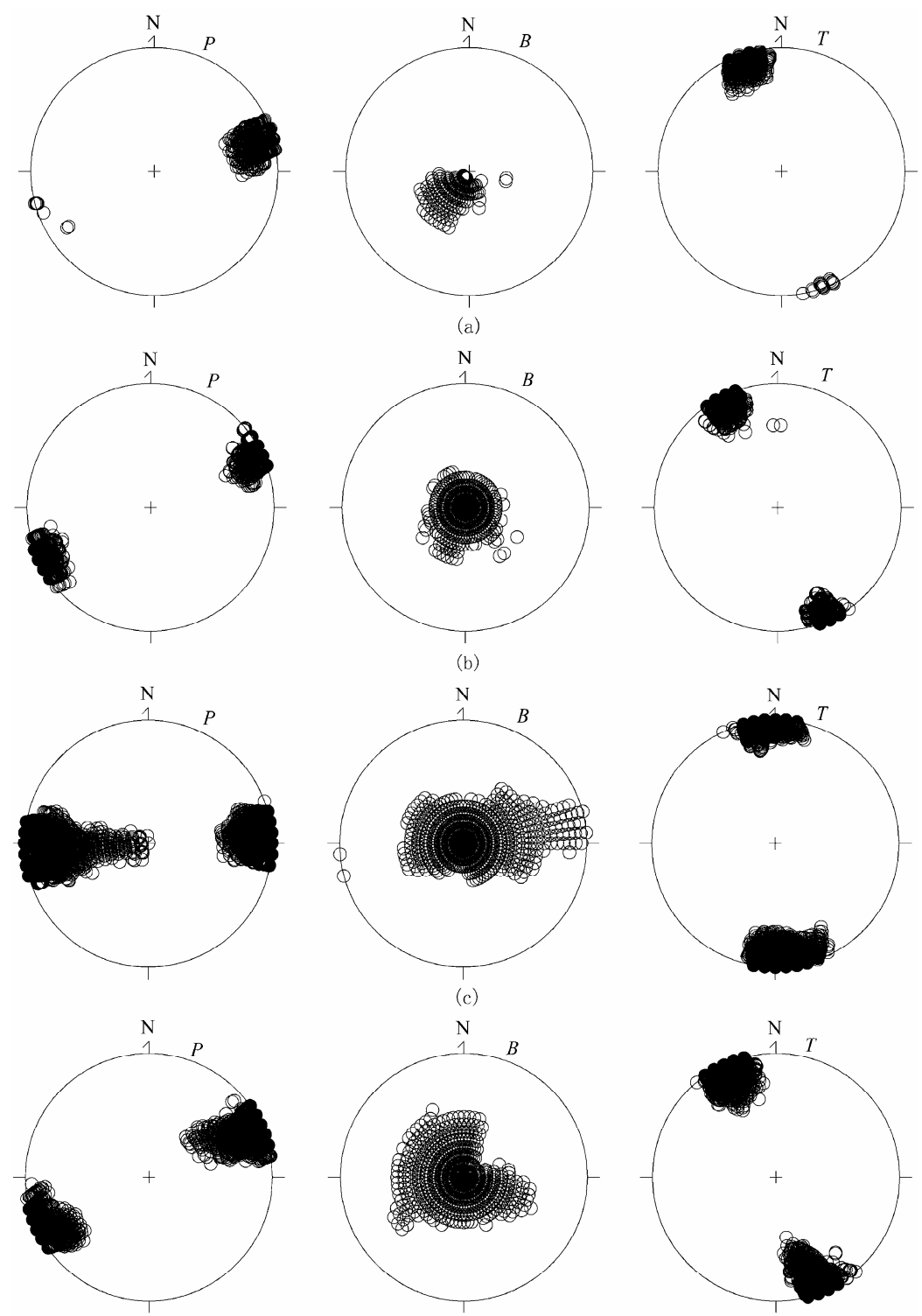

Figure 3 The possible $P, B, T$ axes in 4 sub-districts in the northern area of North China during 2002 2006 (equal-area projection)

(a) Sub-district northwest to Beijing . Number of earthquakes $=59$, the lowest contradiction ratio $=12 \%$;

(b) Beijing sub-district. Number of earthquakes $=36$, the lowest contradiction ratio $=17 \%$; (c) Tangshan sub-district. Number of earthquakes $=208$, the lowest contradiction ratio $=23 \%$; (d) Xingtai sub-district. Number of earthquakes $=128$, the lowest contradiction ratio $=27 \%$

\section{Present stress field in northern a rea of North China changes with time}

XU et al (1983) carried out studies on the heterogeneity of stress field in North China using the P wave first motion polarity data during 1966 1978. They divided North China into 13 sub-districts and obtained the average nodal plane solutions in the 13 sub-districts. The boundaries of sub-district northwest to Beijing, Beijing sub-district, Tangshan sub-district and Xingtai 
sub-district in the 13 sub-districts are not identical to the ones of the four stress sub-districts in this paper, while the scopes are accordant generally. The data of Beijing sub-district and Tangshan sub-district are $\mathrm{P}$ wave first motions polarity of small earthquakes in the ten years before the Tangshan earthquake from 1966 to 1976, the resulted average nodal plane solutions represent the stress state in the two stress sub-districts before the Tangshan earthquake. The time period of data for Xingtai sub-district is from 1972 to 1978, which continued after the 1976 Tangshan earthquake. It is fortunate that these data of Xingtai sub-district are preserved. This thesis selected the data in Xingtai sub-district before Tangshan earthquake from the $\mathrm{P}$ wave first motion polarity data provided by Prof. XU, and carried out re-computation and re-analysis with the grid test method; the average nodal plane solutions and distributions of scatter zone for $P, B$ and $T$ axes from XU et al (1983) and obtained by us do not differ significantly (Figure 4). XU et al (1983) used data from 1971 to 1977 for the sub-district northwest to Beijing, the results were quite in accordance with the average nodal solution from small earthquake data of Shacheng seismic station in this area during 1971 1972 (LI et al, 1973). Therefore, we take the results of sub-district northwest to Beijing, Beijing sub-district and Tanshang sub-district given by XU et al (1983) and the result of Xingtai sub-district obtained in this study as the orientation of mean principal stress axis in the four stress sub-districts before the Tangshan earthquake (Table 3).

Table 3 The directions of mean principal stress axes in the northern area of North China before the Tangshan earthquake (XU et al, 1983)

\begin{tabular}{lcccccc}
\hline \multicolumn{1}{c}{ Sub-district } & Date & $\begin{array}{c}\text { Total number } \\
\text { of symbol }\end{array}$ & $\begin{array}{c}\text { Total number } \\
\text { of earthquake }\end{array}$ & $\begin{array}{c}\text { Orientation of } \\
P \text { axis } /{ }^{\circ}\end{array}$ & $\begin{array}{c}\text { Orientation of } \\
T \text { axis/ }\end{array}$ & $\begin{array}{c}\text { The lowest con- } \\
\text { tradiction ratio }\end{array}$ \\
\hline Sub-district Northwest to Beijing & $1971 \sim 1977$ & 78 & 66 & 75 & 345 & $21 \%$ \\
Beijing Sub-district & $1966 \sim 1976$ & 116 & 102 & 65 & 335 & $21 \%$ \\
Tangshan Sub-district & $1966 \sim 1976-06$ & 81 & 65 & 60 & 330 & $19 \%$ \\
Xingtai Sub-district* & $1972 \sim 1976-05$ & 89 & 59 & 71 & 339 & $13 \%$ \\
\hline
\end{tabular}

Note: * represents results of this thesis.
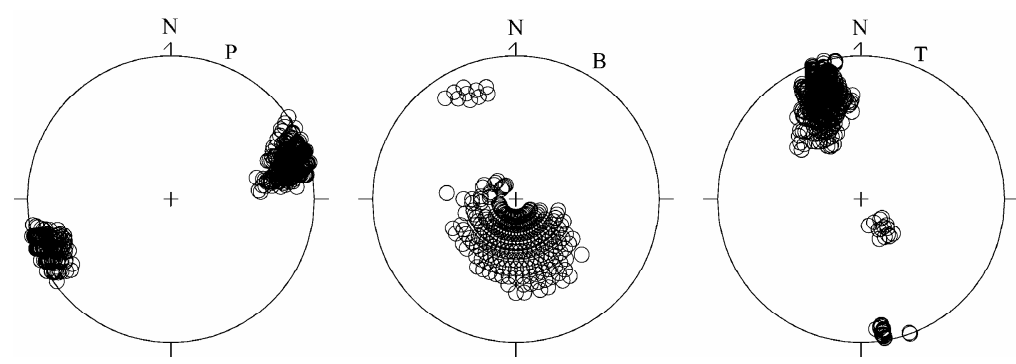

Figure 4 The possible $P, B, T$ axes in Xingtai sub-district during 1972 1976-05 (equal-area projection) Number of earthquakes $=59$, Number of the first motion polarity records $=89$, the lowest contradiction ratio $=13 \%$

The data utilized for analysis and computation in the previous section of this paper are the focal mechanism solutions of moderate and small earthquakes during 2002 2006 in the northern area of North China, which are different from the data utilized by XU et al (1983), but both carried out computations of mean $P, B$ and $T$ axes by grid test method. The results should reflect the recent stress state in the northern area of North China. It can be seen from a comparison between Tables 2 and 3 that the two sets of results are different. There are only small differences in the orientations of $P$ and $T$ axes among the sub-district northwest to $\mathrm{f}$ Beijing, Beijing sub-district, and Xingtai sub-district with the maximum variation not over $5^{\circ}$. The region of the maximum variation 
is Tangshan sub-district: The $P$ axis of average nodal plane solution is NE before the Tangshan earthquake (azimuth $60^{\circ}$ ) and $T$ axis runs NW, while the mean $P$ axis is close to $\mathrm{E}-\mathrm{W}$ (azimuth $267^{\circ}$ ) after the Tangshan earthquake and the mean $T$ axis is close to N-S with a difference approximately $30^{\circ}$ for both $P$ and $T$ axes.

A lot of research results (XU, 1985; JIN and YU, 1987; ZHOU et al, 2001) assumed that the direction of stress field in seismic source area of the Tangshan earthquake was changed after the Tangshan earthquake. As the research methods and data adopted are different, the research results are not consistent. Based on a research of stress field in North China area using focal mechanism solutions of moderate and strong earthquakes, CUI et al (2002) considered that a clockwise rotation of the maximum principal stress in central south area of North China that includes the Tangshan aftershock area may have taken place after the Tangshan earthquake. We carried out an analysis of the selected 236 focal mechanism solutions during 1977 1998 to further investigate the variation feature of present stress field in northern area of North China. For solving the directions of mean $P, B$ and $T$ axes from the focal mechanism solutions in every sub-district, the grid test method is also applied in the computation to facilitate the comparison. The detailed results are shown in Table 4 and Figure 5.

Table 4 The directions of mean principal stress axes in the northern area of North China during 1977 1998 by the grid test method

\begin{tabular}{|c|c|c|c|c|c|c|c|c|c|}
\hline \multirow{2}{*}{ Sub-district } & \multirow{2}{*}{ Date } & \multirow{2}{*}{$\begin{array}{l}\text { Total number } \\
\text { of earthquake }\end{array}$} & \multicolumn{2}{|c|}{ Mean $P$ axis $/^{\circ}$} & \multicolumn{2}{|c|}{ Mean $B$ axis $/^{\circ}$} & \multicolumn{2}{|c|}{ Mean $T$ axis $/^{\circ}$} & \multirow{2}{*}{$\begin{array}{l}\text { The lowest } \\
\text { contradic- } \\
\text { tion ratio }\end{array}$} \\
\hline & & & Azimuth & Inclination & Azimuth & Inclination & Azimuth & Inclination & \\
\hline $\begin{array}{l}\text { Sub-district North- } \\
\text { west to Beijing }\end{array}$ & $1978 \sim 1998$ & 40 & 70 & 12 & 275 & 76 & 161 & 6 & $25 \%$ \\
\hline Beijing Sub-district & $1977 \sim 1989$ & 82 & 80 & 0 & 354 & 86 & 170 & 4 & $24 \%$ \\
\hline Tanshan Sub-district & $1977 \sim 1995$ & 91 & 86 & 3 & 344 & 77 & 177 & 12 & $24 \%$ \\
\hline Xingtai Sub-district & $1977 \sim 1997$ & 23 & 85 & 18 & 322 & 58 & 184 & 25 & $26 \%$ \\
\hline
\end{tabular}

It can be seen from Table 4 and Figure 5 that the lowest contradiction ratios of the four stress sub-districts are all around $25 \%$. The scatter zones of possible $P, B$ and $T$ axes in sub-district northwest to Beijing, Beijing sub-district, and Tangshan sub-district are basically symmetric except for the Xingtai sub-district. The data of focal mechanism solutions constrained satisfactorily the mean $P, B$ and $T$ axes. As the data of Xingtai sub-district is sparse with only 23 focal mechanism solutions, the scatter zone of possible $P, B$ and $T$ axes is much wider and the distribution is not so symmetric, which means the reliability of the result for Xingtai sub-district is relatively poor. Generally speaking, the mean $P, B$ and $T$ axes in every sub-district can represent the state of stress field in the stress sub-strict in the time period.

The computation result of this paper shows that the mean $P$ axes of every time period in the four stress sub-districts are all near to horizontal (Tables 2 and 4, Figures 3, 4 and 5). XU et al (1983) only presented the directions of $P$ and $T$ axes of the average nodal plane solutions in their paper, but not the inclination values. However, it can be seen from their result (Figure 5 in XU et $a l, 1983)$ that the $P$ axis of average nodal plane solutions in sub-district northwest to Beijing, Beijing sub-district, and Tangshan sub-district are all near to horizontal. For this reason, we collect the directions of mean $P$ axis of several earthquakes in different time periods in northern area of North China and the directions of $P$ axes from the average nodal plane solutions of small earthquakes, that is, put together the directions of $P$ axes of Tables 2, 3, and 4 in Figure 6, from which we could get a clear view of varying feature of stress field changing with time in northern area of North 

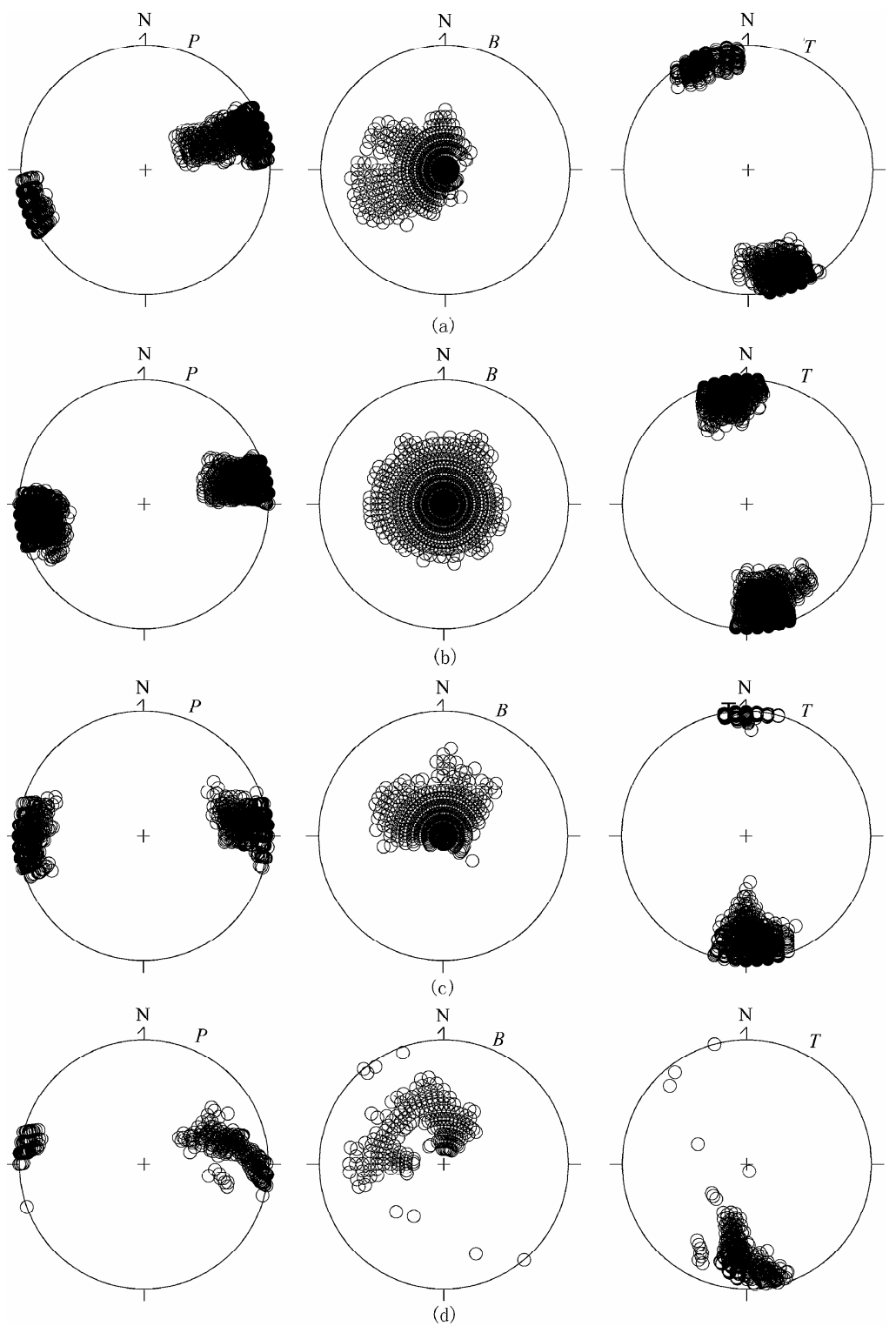

Figure 5 The possible $P, B, T$ axes in four sub-districts in the northern area of North China during 1977 1998 (equal-area projection)

(a) Sub-district northwest to Beijing. Number of earthquakes $=40$, the lowest contradiction ratio $=25 \%$; (b) Beijing sub-district. Number of earthquakes $=82$, the lowest contradiction ratio $=24 \%$; (c) Tangshan sub-district. Number of earthquakes $=91$, the lowest contradiction ratio $=24 \%$; (d) Xingtai sub-district. Number of earthquakes $=23$, the lowest contradiction ratio $=26 \%$

China from 1960s to the beginning of this century. The directions of $P$ axes in all stress sub-districts are all around $60^{\circ} \sim 75^{\circ}$ before the 1976 Tangshan earthquake, after the quake, the direction of $P$ axis in Tangshan sub-district rotated about $30^{\circ}$, and stays near-E-W since then; the direction of $P$ axis in Beijing sub-district rotated also by a relatively small value of $15^{\circ}$; after 2002 the direction of $P$ axis returned to NE; Xingtai sub-district is similar to Beijing sub-district, the direction of $P$ axis turned to near-E-W, while after 2002 the direction turned back to NE; the direc- 
tion of $P$ axis in sub-district northwest to Beijing in the recent decades is relatively stable $\left(70^{\circ} \sim 75^{\circ}\right)$, and has no significant changes.

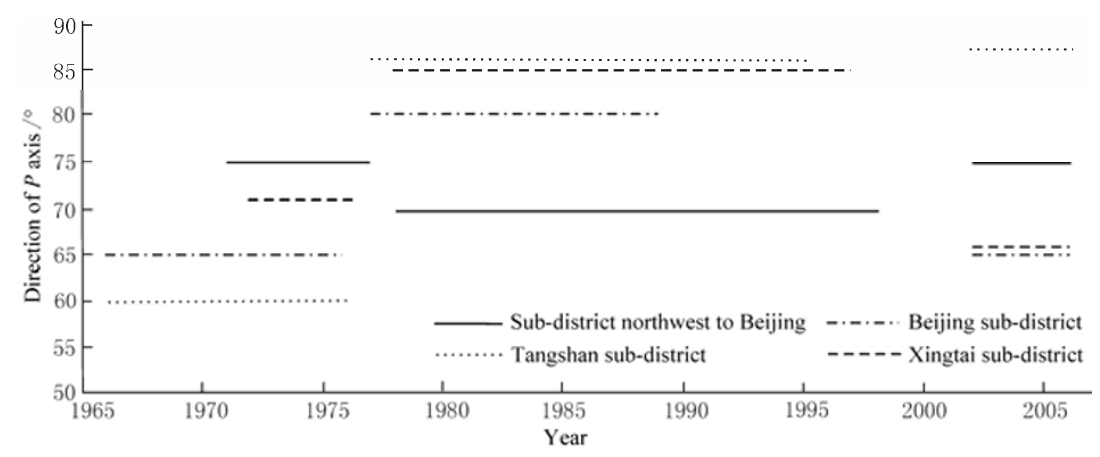

Figure 6 The temporal changes of directions of $P$ axes in four sub-districts in the northern area of North China

\section{Discussion and conclusions}

Firstly, the paper carried out analysis and computation on the mean principal stress axis using the data of moderate and small earthquakes during 2002 2006 in the four stress sub-districts in northern area of North China by grid test method. The results show that the mean $B$ axis (medium principal stress axis) is vertical basically; the mean $P$ axis (the maximum principal stress axis) and mean $T$ axis (the minimum principal stress axis) are near horizontal; the direction of the maximum principal stress axis is NE-SW and near-E-W, and the direction of the minimum principal stress axis is NW-SE and near-S-N, which shows that horizontal action dominates the present stress field in northern area of North China, and the general features of the present stress field in northern area of North China presented by the mean principal stress axis are in accordance with the results in the past.

Secondly, the paper investigated the temporal variation feature of present stress field in northern area of North China using the mean principal stress axes obtained from focal mechanism solutions in northern area of North China during 1977 1998 and during 2002 2006. The analysis results further supports that the direction of principal stress rotated after the M7.8 Tangshan earthquake in 1976 in Tangshan seismic source area as well as in the neighboring Beijing and Xingtai sub-districts; the mean $P$ axis of focal mechanism solution rotated about $15^{\circ} \sim 30^{\circ}$ clockwise, while the present stress field in sub-district northwest to Beijing at the west section of Zhangjiakou-Bohai Fault Belt is relatively stable in the researched period, and the direction of principal stress in sub-district northwest to Beijing did not change much after the Tangshan earthquake. It should be pointed out that the focal mechanism solutions in Xingtai sub-district during 1977 1998 are fewer (23 solutions only), the reliability of its result still need to be tested by more data.

The analysis results presented in this paper also give an interesting changing image of stress field in northern area of North China: The direction of mean $P$ axis of focal mechanism solution in Beijing sub-district during 2002 2006 is $65^{\circ}$, while the direction of mean $P$ axis in Xingtai subdistrict in the same period is $66^{\circ}$, which are quite coherent with the $P$ axis of average nodal plane solutions before Tangshan earthquake, the stress field in these two stress sub-districts seems to have rotated back to the state before the Tangshan Earthquake. However, the mean $P$ axis of focal mechanism solution in Tangshan sub-district stays in E-W direction all along after the quake. 
It can be seen from Figure 2 that the data of focal mechanism solutions used in this paper are discontinuous in time, the focal mechanism solutions in northern area of North China (mainly the sub-district northwest to Beijing and Xingtai sub-district) during 1977 1998 are relatively fewer, especially during 1990 2001 there were only a few focal mechanism solutions, therefore it is hard to make specific analysis on the process of adjusting and changing of stress field in the northern area of North China. The direction feature of stress field in the northern area of North China in two time periods after the Tangshan earthquake was analyzed in this paper by the grid test method, and a simple comparison was made with the average nodal plane solutions in northern area of North China before the Tangshan earthquake by XU et al (1983). As the data sources used in the three time periods are different, the analysis results of this paper give only a possible preliminary image of the adjusting and changing of stress field in the northern area of North China in recent several decades, requiring more data and researches to prove.

In addition, the paper does not involve the dynamic mechanism of stress field adjusting and changing and its relation with strong earthquakes, further studies are required.

Acknowledgement We express sincere gratitude to Prof. XU Zhong-huai for providing the source program of computation for grid test method and first motion polarity data of $\mathrm{P}$ wave in the Xingtai sub-district during 1972 1976.

\section{References}

CHEN lian-wang, YANG Shu-xin, XIE Fu-ren. 2003. Annual changes of tectonic stress filed in North China block [M]//Crustal Stress in China. Beijing: Geological Publishing House: 105-117 (in Chinese).

CUI Xiao-feng and XIE Fu-ren. 2002. The spatial and temporal variation of modern tectonic stress field in North China before and after the 1976 Tangshan earthquake [J]. Earthquake Research in China, 16(1): 71-80 (in Chinese).

DIAO Gui-ling, GAO Guo-ying, NIE Xiao-hong, et al. 2007. Analysis on the focal mechanism of small and medium earthquakes in Jiashi sequence [J]. Recent Developments in World Seismology, (12): 1-9 (in Chinese).

FAN Jun-xi, MA Jin, DIAO Gui-ling. 2003. Contemporary tectonic stress field around the Ordos fault block inferred from earthquake focal mechanisms [J]. Seismology and Geology, 25(1): 88-89 (in Chinese).

FANG Ying, JIANG Zai-sen, ZHANG Jing, et al. 2008. Analysis of current movement of Zhangjiakou-Bohai fault zone [J]. Journal of Geodesy and Geodynamics, 28(1): 11-15 (in Chinese).

GUO Liang-qian, MA Qing, YANG Guo-hua. 2007. Contemporary motion and strain of major tectonic zones in north China [J]. Recent Developments in World Seismology, (7): 68-75 (in Chinese).

HU Xin-liang, DIAO Gui-ling, MA Jin, et al. 2004. Reliability analysis of focal mechanism solutions of micro-earthquakes determined from amplitude ratio of $\bar{P}$ and $\bar{S}$ recorded by digital seismograph [J]. Seismology and Geology, 26(2): $347-354$ (in Chinese).

JIN Ya-min and YU Xin-chang. 1987. Dynamic variation of composite fault plane solution of small earthquakes in the north China [J]. Seismology and Geology, 9(4): 19-31 (in Chinese).

LI Qin-zu, WANG Ze-gao, JIA Yun-nian, et al. 1973. Stress filed obtained for two regions from weak earthquakes data recorded at a single seismic station [J]. Acta Geophysica Sinica, 16(1): 49-61 (in Chinese).

LI Qin-zu. 1980. General features of the stress field in the crust of North China [J]. Acta Geophysica Sinica, 23(4): $376-388$ (in Chinese).

LIANG Shang-hong, LI You-ming, SHU Pei-yi, et al. 1984. On the determining of source parameters of small earthquakes by using amplitude patios of $\bar{P}$ and $\bar{S}$ from regional network observations [J]. Acta Geophysica Sinica, 27(3): $249-257$ (in Chinese).

WANG Kai-ying, MA Jin, GU Guo-hua, et al. 2003. Rotation of stress axis in Sichuan-Yunnan region in 1996 [J]. Earth Science Frontiers, 10 (Special): 231-239 (in Chinese).

WANG Ruo-bai, GU Guo-hua, XU Jie, et al. 2004. Discussion on characteristics of crustal deformation along the Zhangjiakou-Bohai seismic tectonic zone [J]. Seismology and Geology, 26(4): 586-596 (in Chinese).

WANG Sheng-zu and ZHANG Liu. 2002. Tectonic stress field and seismic tectonics controlled by plastic-flow network in North China [J]. Seismology and Geology, 24(1): 69-80 (in Chinese).

WANG Su-yun and XU Zhong-huai. 1985. Seismo-tectonic stress field in east China [J]. Acta Seismologica Sinica, 47(4): 654-662 (in Chinese).

XIE Fu-ren, CUI Xiao-feng, ZHAO Jian-tao, et al. 2004. Regional division of the recent tectonic stress field in China and adjacent areas [J]. Chinese J Geophys, 47(4): 654-662 (in Chinese).

XU Zhong-huai, YAN Ming, ZHAO Zhong-he. 1983. Evaluation of the direction of tectonic stress in North China form recorded data of a large number of small earthquakes [J]. Acta Seismologica Sinica, 5(3): 268-279 (in Chinese).

XU Zhong-huai. 1985. Mean stress field in Tangshan aftershock area obtained from focal mechanism data by fitting slip directions [J]. 
Acta Seismologica Sinica: 7(4): 349-362 (in Chinese).

ZHAO Gen-mo, CHU Bao-long, GUO Rui-zhi. 1984. The change of orientation of stress of the minor earthquakes before the strong Ninghe earthquake of 1976 [J]. Acta Seismologica Sinica, 6(4): 414-424 (in Chinese).

ZHONG Ji-mao and CHENG Wan-zheng. 2006. Determination of directions of the mean stress field in Sichuang-Yunnan region from a number of focal mechanism solutions [J]. Acta Seismologica Sinica, 19(4): 359-369.

ZHOU Cui-ying, CHEN Hong, WANG Hong-wei, et al. 2000. Comprehensive analysis of dynamic evolution characteristics of stress field before moderate and strong earthquakes [J]. Earthquake, 20(2): 27-36 (in Chinese).

ZHOU Cui-ying, WANG Hua-lin, WANG Hong-wei, et al. 2001. The changes of stress field in the focal region and its adjacent areas before four moderate-strong earthquakes in North China [J]. Seismology and Geology, 23(1): 98-110 (in Chinese).

Yamakawa N. 1971. Stress fields in focal regions [J]. J Phys Earth, 19: 347-353. 